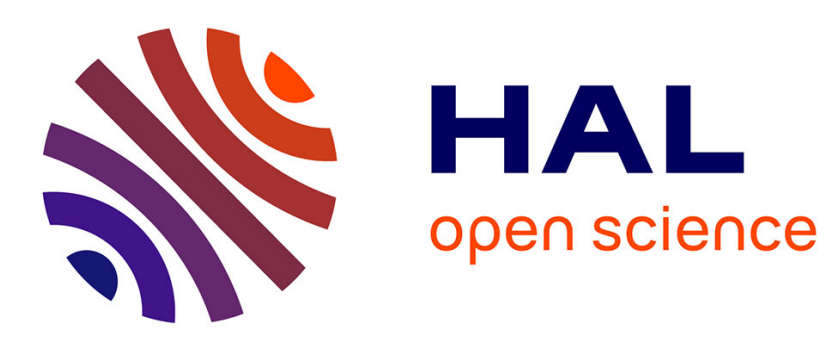

\title{
Nanoplastics Identification in Complex Environmental Matrices: Strategies for Polystyrene and Polypropylene
}

Florent Blancho, Mélanie Davranche, Hind El Hadri, Bruno Grassl, Julien Gigault

\section{- To cite this version:}

Florent Blancho, Mélanie Davranche, Hind El Hadri, Bruno Grassl, Julien Gigault. Nanoplastics Identification in Complex Environmental Matrices: Strategies for Polystyrene and Polypropylene. Environmental Science and Technology, 2021, 55 (13), pp.8753-8759. 10.1021/acs.est.1c01351 . insu03259279

\section{HAL Id: insu-03259279 \\ https://hal-insu.archives-ouvertes.fr/insu-03259279}

Submitted on 17 Jun 2021

HAL is a multi-disciplinary open access archive for the deposit and dissemination of scientific research documents, whether they are published or not. The documents may come from teaching and research institutions in France or abroad, or from public or private research centers.
L'archive ouverte pluridisciplinaire HAL, est destinée au dépôt et à la diffusion de documents scientifiques de niveau recherche, publiés ou non, émanant des établissements d'enseignement et de recherche français ou étrangers, des laboratoires publics ou privés. 


\title{
Nanoplastics identification in complex environmental matrices: Strategies for polystyrene and polypropylene
}

\author{
Florent Blancho ${ }^{\mathrm{a}}$, Mélanie Davranche ${ }^{\mathrm{a}}$, Hind El Hadri ${ }^{\mathrm{c}}$, Bruno Grassl ${ }^{\mathrm{c}}$ and Julien Gigault ${ }^{\mathrm{a}, \mathrm{b}, \dagger,{ }^{*}}$ \\ ${ }^{a}$ Géosciences, CNRS / Université Rennes 1, UMR 6118, F35000 Rennes, France \\ bTAKUVIK, CNRS / Université Laval, UMI3376, Québec, G1V 0A6, Canada \\ 'IPREM, CNRS / Université de Pau et des Pays de 1'Adour, F64000 Pau, France
}

Corresponding author :

Julien Gigault, julien.gigault@takuvik.ulaval.ca (ORCID: 0000-0002-2988-8942)

\begin{abstract}
Identification of nanoplastics in complex environmental matrices remains a challenge. Despite the increase in nanoplastics studies, there is a lack of studies dedicated to nanoplastics detection, partially explained by their carbon-based structure, their wide variety of composition, and their low environmental concentrations compared to the natural organic matter. Here, pyrolysis coupled to a GCMS instrumental setup provided a relevant analytical response for polypropylene and polystyrene nanoplastic suspensions. Specific pyrolysis markers and their indicative fragment ions were selected and validated. Possible interferences with environmental matrices were explored by spiking nanoplastics in various organic matter suspensions (i.e., algae, soil natural organic matter, and soil humic acid) and analyzing an environmental suspension of nanoplastics. While a rapid polypropylene nanoplastics identification was validated, polystyrene nanoplastics require preliminary treatment. The here presented strategies open new possibilities to the detection/identification of nanoplastics in environmental matrices such as soil, dust, and biota.
\end{abstract}

\section{Keywords}

Nanoplastics, polypropylene, Py-GCMS, identification, OM interference, complex matrices. 


\section{Introduction}

Under environmental conditions, all plastic debris is likely to release many nanoplastics (NPs) under multiple physicochemical degradation pathways ${ }^{1-3}$. While the scientific community is now admitting the occurrence of NPs in the environment, relatively few studies demonstrated their presence ${ }^{4-6}$. When the material reaches the nanoscale, its properties, reactivity, and impact are significantly enhanced, especially for plastic debris due to its considerable heterogeneity in composition $^{7-9}$. The plastic debris regroups an extensive range of materials which complexifies the analytical and environmental challenge. This challenge is even more complex when the size of the plastic debris is under the optical resolution ${ }^{8,9}$. Each plastic family, composition, and size require specific attention and dedicated strategy as performed this last century for a wide range of contaminants.

Among the various plastics produced globally, polypropylene and polystyrene represent approximately 20 to $30 \%$ of the total production ${ }^{10}$. Polypropylene plastic debris are detected in diverse environmental compartments ${ }^{10,11}$. For instance, Reisser et al. ${ }^{12}$ found approximately $30 \%$ polypropylene in plastic debris collected on the Australian sea coast. Brignac et al. ${ }^{13}$ consistently found a significant proportion of polypropylene pieces (i.e., $>15 \%$ ) on beaches, sea surface, and seafloor. In terrestrial environments, polypropylene microplastics (MPs) have been reported in sewage sludge ${ }^{14}$, sediments, and suspended matter in rivers ${ }^{15}$. While Polystyrene-based plastics represent more than $96 \%$ of the plastic debris investigated in the literature, it represents less than $6 \%$ of the plastic found in the environment ${ }^{16,17}$.

At the nanoscale, determining plastic debris occurrence in complex environmental media is highly challenging due to their small size and ability to heteroaggregates with the natural organic matter (NOM) and the inability to physically separate them (NPs vs. NOM) by filtration or other processes $^{18}$. As recently explained, when reaching the nanoscale, the volume of NOM related to the plastics increases exponentially. Therefore, analytical strategies used to characterize microscale cannot be extrapolated to the nanoscale plastic debris.

Among the available analytical methods, pyrolysis coupled to gas chromatography and mass spectrometry proved the presence of polyethylene NPs in the colloidal fraction of the North Atlantic Ocean gyre (NAOG) ${ }^{4}$. However, we could not detect polypropylene markers in the colloid fraction, while this plastic is present in the microplastic fraction. Two reasons were invoked: 1) low polypropylene abundance and 2) modification of the pyrolysis products of nanoscale polypropylene. To date, no PyGCMS pyrogram is provided for colloidal polypropylene in the literature., Potential variations in pyrolysis products at the nanoscale are thus unknown. Polystyrene NPs are identified in $\mathrm{NAOG}^{4}$, coast exposed to the $\mathrm{NAOG}^{5}$, and contaminated soil ${ }^{6}$. However, as for polypropylene under complex environmental conditions, interferences with OM were encountered, especially for their primary direct markers, styrene, and toluene ${ }^{19,20}$. While authors are looking for the styrene dimers as proof of the polystyrene presence, as observed for a large fragment of polyethylene, it is less probable to found such pyrolyze products at the nanoscale due to the considerable heterogeneity of the NOM. One way to by-pass such a limitation is to investigate the pyrolyzates ratio to detect the presence of the plastics in $\mathrm{NOM}^{21}$. Moreover, the problem is even more complicated as, in addition to pyrolyzates interferences, we demonstrated that the NOM also attenuates the global signal ${ }^{6}$. A critical preliminary investigation of the possible interferences with NOM has therefore to be performed.

Therefore, this study aims to explore polystyrene and polypropylene NPs identification in the presence of different NOM by PyGCMS. Two different and complementary strategies are developed and proposed according to the plastics composition and the NOM. Based on a careful 
investigation of chromatograms in terms of pyrolyzate and retention time. We demonstrate that polypropylene NPs can be directly identified in complex media. However, for polystyrene NPs, we needed to develop a protocol for purifying the environmental sample from NOM to obtain a reliable detection of polystyrene in complex media. The method is finally applied on an environmentally-relevant NPs suspension obtained from plastic debris altered under environmental conditions and covered by NOM. While we use the pyrolysis library to identify polypropylene NPs, polystyrene NPs are detected in the environmental sample according to the relative ratio of its principal pyrolyzates.

\section{Materials and methods}

\section{Samples}

Polystyrene and polypropylene pellets were purchased from Sigma Aldrich and were used as reference materials for PyGCMS and to produce nanoplastics. Natural organic matter standards are purchased from IHSS (International Humic Substances Society, and, respectively): leonardite NOM (LNOM, references 1S104H), leonardite Humic Acid (LHA, reference 1BS104L). LNOM and LHA were solubilized in $1 \mathrm{~mol} \mathrm{~L}^{-1}$ of $\mathrm{NaOH}$ (Sigma Aldrich) (1:10 ratio in $\mathrm{g} / \mathrm{g}$ ) for $24 \mathrm{~h}$. Additionally, to these NOM standards, fresh organic matter is prepared from Sargasso algae residue (Sainte-Marie Bay, Guadeloupe, France). The organic matter of Sargasso algae (SAWE) was obtained by stirring $1 \mathrm{~g}$ of algae in ultrapure water $(1: 10$ ratio in $\mathrm{g} / \mathrm{g}$ ) for $24 \mathrm{~h}$ and filtered at 3 $\mu \mathrm{m}$ ( Pall) ${ }^{22}$. The total organic carbon concentration (TOC) of all the organic matter solutions was quantified by a TOC-analyzer (TOC-V analyzer, Shimadzu).

\section{$\underline{\text { Nanoplastics preparation }}$}

Polypropylene and polystyrene NPs are produced using a top-down mechanical degradation as previously described ${ }^{23}$. Briefly, plastic pellets were fragmented using a planetary ball mill (Pulverisette 7, Fritsh GmdH) with a 5 or $10 \mathrm{~mm}$ diameter zirconium oxide ball. The fragmented polypropylene and polystyrene powders are freeze-dried (Alpha 3-4, Christ). Then, the powders are redispersed in water and filtered at $3 \mu \mathrm{m}$ (polyethersulfone membrane, Pall) to remove microsized-particles. Additionally, environmentally relevant nanoplastics, namely environmental NPs (EnvNPs), were produced from plastic debris collected in the environment ${ }^{24}$. Plastic debris were randomly collected on Saint Marie Bay's beach (Guadeloupe, France) in September 2018 (Figure 1) ${ }^{13}$. This beach receives plastic debris and Sargassum Algae (brown line on Fig. 1b and 1c) from the $\mathrm{NAOG}^{5}$. Briefly, $100 \mathrm{~g}$ of plastic debris was stirred in ultrapure water (1:5 ratio) for 2 days (KS 15A, Edmund Bühler $\mathrm{GmbH}$ ), sonicated for 5 days (TP 680/DH, Elma GmbH), and finally filtered at $3 \mu \mathrm{m}$ (PTFE, Pall). To be in the range of analytical ability of the here-used methods and when necessary, the mass of the colloids (analyzed nanoplastics and NOM) was concentrated using an ultrafiltration system (Amicon, Merck Millipore) equipped with a $20 \mathrm{kDa}$ cut-off membrane (PES, Microdyn NADIR). To purify the nanoplastics from the NOM, solutions were oxidized by $\mathrm{H}_{2} \mathrm{O}_{2}$ and UV. The UV (UVC) was used within the range of 24h (RMR-600, Rayonet). As beached plastics were primarily associated with sand and sargassum algae residues (see supplemental information, Figure S1), a significant amount of natural organic matter is released and dispersed with the nanoplastics produced. All the final dispersions were kept in the dark and at $4^{\circ} \mathrm{C}$ and remain stable over 3 weeks. 

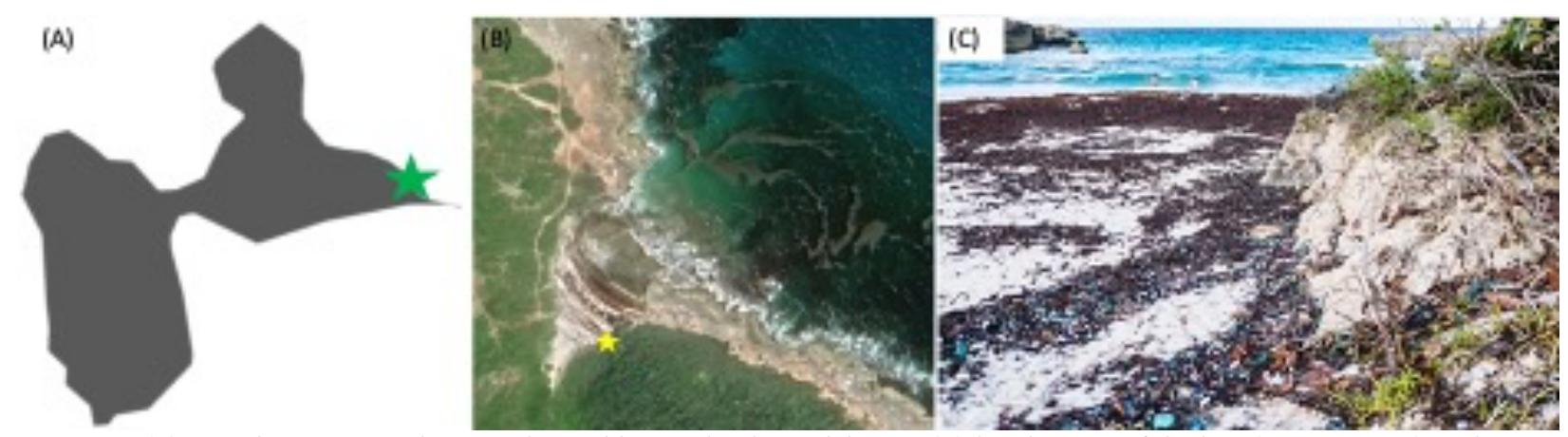

Figure 1: (A) Sampling area on the French Caribbean Island Guadeloupe; (B) localization of the bay (Sainte Marie) at the GPS coordinate 16 16'24" N-61 14'35" W with the brown line is corresponding to the Sargassum Algae coming from the oceans (CNES); (C) pictures of the sampling site where the plastic debris are identified and mixed with the Sargassum Algae (CNRS, Cyril Fresillon).

\section{Size and shape characterization}

The hydrodynamic size distribution of the NPs and EnvNPs was determined using optical fiber dynamic light scattering (DLS). Measurements are performed with a VASCO Flex (Cordouan Technologies, France). The size distribution of NPs is determined by fitting the autocorrelation function (ACF) with Padé-Laplace and Spare Bayesian Learning algorithm ${ }^{25,26}$. Each DLS analysis is carried out with six replicates with an analysis period of $120 \mathrm{~s}$. Only results for replicates with reliable residuals $(r<0.01)$ were accepted. The ACF samples are compared to 200, 500, and 900 $\mathrm{nm}$ polystyrene spherical latex nanoparticles (Thermo Scientific). The shape of the NPs is examined using a Jeol JEM $2100 \mathrm{HR}$ electron microscope in transmission mode (TEM) after drying $2.5 \mu \mathrm{L}$ of suspension onto a carbon grid (Oxford Instrument). Images are acquired with a Gatan Orius SC200D camera, and elemental analysis is performed using an EDX Oxford X-Max $80 \mathrm{~T}$ detector.

Nanoplastics molecular identification

NPs suspensions (Polypropylene, Polystyrene, and EnvNPs) and the NOM were analyzed by pyrolysis (PY-3030, Frontier Lab) coupled to gas chromatography and a mass spectrometry detector (Py-GCMS) (5977B, Agilent Technologies). Before Py-GCMS analysis, liquid samples are evaporated at $45^{\circ} \mathrm{C}$ in an $80 \mu \mathrm{L}$ pyrolysis cup (Frontier Lab). The mass of prepared nanoplastics was fixed at $2 \mu \mathrm{gC}$ in the pyrolysis cup. Concerning the NOM, the mass was ranged from 25 to $175 \mu \mathrm{gC}$. To assess any polymer contamination during the sample preparation (i.e., drying process), empty pyrolysis cups were systematically added beside regular samples. The optimal GC conditions were fixed according to the method of Dehaut et al. ${ }^{27}$. The pyrolysis was performed at $600^{\circ} \mathrm{C}$. Once pyrolyzed, samples were injected (splitless) into a 30m DB5 capillary column (Agilent Technologies) using helium as the carrier gas. The column temperature was fixed at $50^{\circ} \mathrm{C}$ for $10 \mathrm{~min}$, increased to $275^{\circ} \mathrm{C}$ at a rate of $5^{\circ} \mathrm{C} / \mathrm{min}$, and finally kept at this temperature for $15 \mathrm{~min}$. Separated pyrolysis products were ionized at $70 \mathrm{eV}$, and their mass spectra were analyzed between $\mathrm{m} / \mathrm{z} 33$ to 500. Pyrolyzates signals are compared to the NIST library and personal library builds using plastic pellets described above. Each pyrograms were realized in four replicates. As it is not yet possible to quantify nanoplastics by PyGCMS, we determined the signal-to-noise ratio (SNR), 
ranging from 150 to 430, for all performed analyses. Based on the SNR and the mass of nanoplastics ${ }^{28}$, LOD can be estimated from 0.2 to $0.4 \mathrm{mgC} \mathrm{L}^{-1}$.

\section{Results and Discussions}

Nanoscale effects on plastic pyrolysis.

The size and shape of polypropylene and polystyrene NPs used in these studies were described in the supplemental information (Figure S2). For both suspensions, NPs present a different population with $\mathrm{d}_{\mathrm{H}}<1 \mu \mathrm{m}$. It is worth noting that hydrodynamic diameter depends on the geometric size (radius) and the shape of materials ${ }^{29,30}$. Therefore, asymmetrical materials can present different diffusion (transversal and rotational), which results in different apparent populations on the size distribution ${ }^{30}$. All NPs suspensions present anisotropic and heterogeneous shapes with spherical equivalent sizes less than $1 \mu \mathrm{m}$. For polypropylene NPs, fine particles (size $>200 \mathrm{~nm}$ ) were identified as NPs, and opaque particles as inorganic species $(<200 \mathrm{~nm})$, as confirmed by EDX analysis (Figure S3). These species are principally titanium oxide, known to be one of the major plastic additives ${ }^{31}$. No inorganic species were identified into polystyrene NPs, which is explained by their virgin pellet source. Based on the polypropylene pyrolysis at a microscale (see SI, Figure S4 and Table S1), four distinctive peaks are pre-selected: the C9 (2,4-dimethyl-1-heptene), the C12 (meso-2,4,6-trimethyl-1-nonene), the C15i (isotactic-2,4,6,8-tetramethyl-1-undecene) and the C15s (syndiotactic-2,4,6,8-tetramethyl-1-undecene). The pyrolyzates C9 and the C15s have already been documented as a polypropylene marker in environmental studies ${ }^{4,15,14,32,33}$. Based on a literature comparison ${ }^{14,34}$, none of these markers were obtained for various NOMs. The pyrograms of polypropylene NPs (TIC, $m / z 70$ and 69) are plotted in Figure 2. The $m / z 70$ pyrogram specifically enhanced the marker C9, whereas the $\mathrm{m} / \mathrm{z} 69$ enhanced the other polypropylene pyrolyzates (i.e., C10, C12, C15i, and C15s). Peaks are observed at the retention times of all the selected polypropylene markers (Figure 2A). The mass spectrum of polypropylene NPs obtained at the characteristic retention times (blue bar) werecompared with the polypropylene library (red bar). For C9, C12, and both $\mathrm{C} 15$ compounds, mass spectra were significantly similar to the library ones (Spectrum Similarity, SS > 0.90). Although these markers are found on both micrometric pellet and NPs pyrolysis, their relative peak areas vary significantly (i.e., Table S1). For polypropylene NPs, the proportion of $\mathrm{C} 12, \mathrm{C} 15 \mathrm{i}$, and $\mathrm{C} 15 \mathrm{~s}$ increases by a factor of 2-3 compared to MPs pellets. Based on this result, $\mathrm{C} 9, \mathrm{C} 12$, and $\mathrm{C} 15$ compounds are the most relevant for identifying polypropylene at the nanoscale.

For polystyrene NPs identification, seven distinctive peaks were pre-selected from the microscale pellet pyrolysis (see SI, Fig. S5): toluene, styrene, $\alpha$-methyl styrene, bibenzyl, styrene dimer, 2phenyl naphthalene, and styrene trimer. Only two pyrolyzates differ from the pyrolysis of literature and hereafter studied organic matter (Table S2): styrene dimer and trimer. The $\mathrm{m} / \mathrm{z} 104$ pyrogram specifically enhanced the styrene, whereas the $m / z 91$ pyrogram enhanced the styrene dimer and trimer. Only significant peaks at the styrene and styrene dimer's retention time were studied (see SI, Fig. S6). Their mass spectra were similar to the library spectra. Oppositely, the styrene trimer mass spectra are noisily due to their low abundance and the limit of detection. From polystyrene MPs to NPs, the proportion of styrene dimer and trimer decreased from $26 \%$ to $0.2 \%$ and $23 \%$ to a negligible area. One hypothesis to explain such result, as we previously observed for polyethylene ${ }^{4}$, is that the probability of forming a large mass of pyrolyzate (i.e., $\mathrm{m} / \mathrm{z}>200$ ) considerably decreases from the microscale to the nanoscale. 

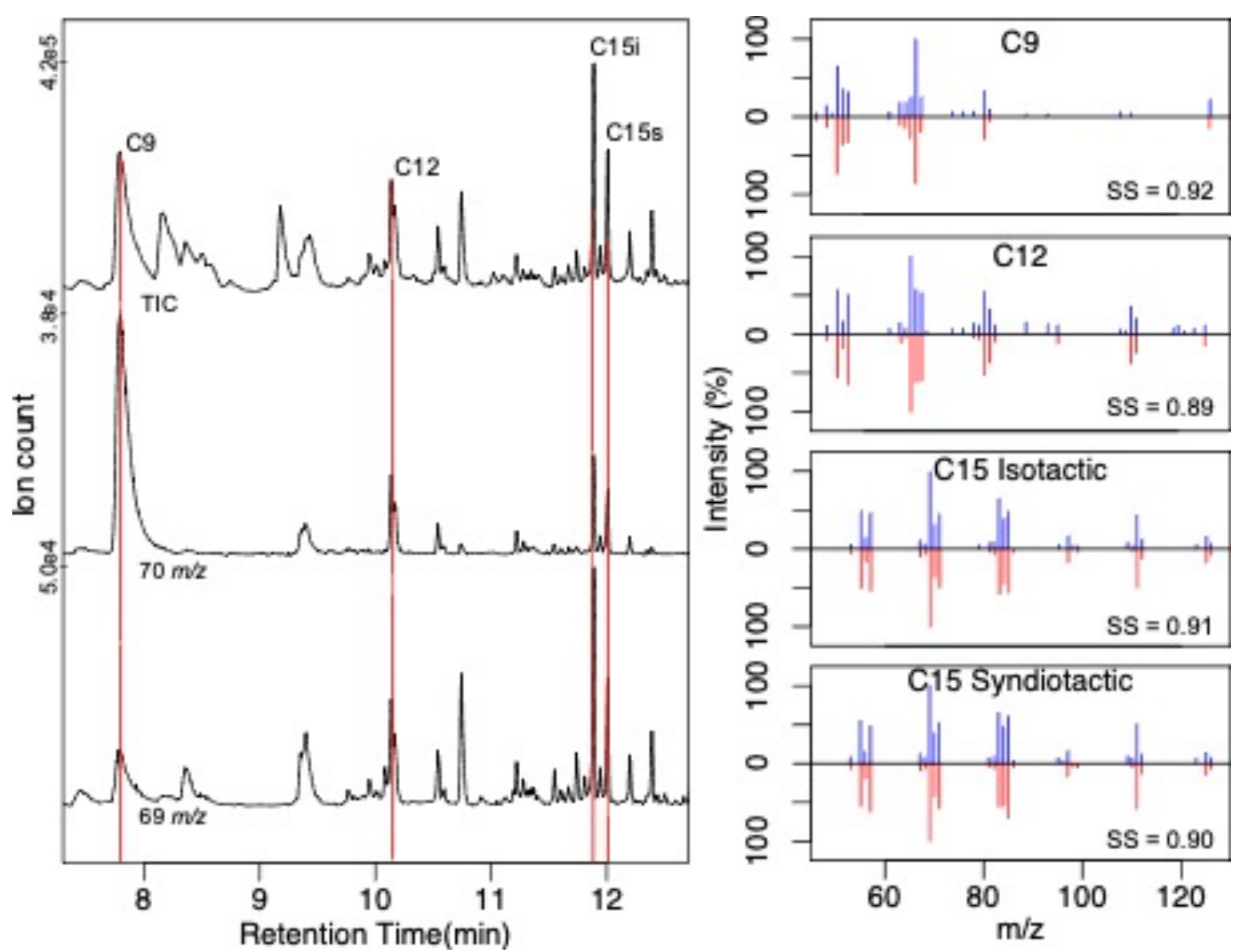

Figure 2: (A) polypropylene NPs pyrograms for all TIC, $\mathrm{m} / \mathrm{z} 70$ and $\mathrm{m} / \mathrm{z}$ 69. (B) Mass spectra comparison between the MSs of pyrolyzates recorded at the PP marker retention times (blue) and their library MSs (red).

Since the direct identification of polystyrene NPs is based on both pyrolyzates, the decreasing size from polystyrene MPs to NPs would affect the polystyrene NPs detection in environmental matrices. Regarding their nanoscale, low quantity, and ability to hetero-aggregate with the NOM, the direct identification of polystyrene NPs in environmental matrices seems impossible. Polystyrene identification should thus integrate an indirect identification. An alternative is to determine the absolute pyrolyzate ratio of toluene/styrene ${ }^{35,21}$. This ratio is $<0.01$ for pristine polystyrene and $>4-5$ for organic matter ${ }^{21,35}$.

\section{Natural organic matter contribution}

Although few pyrolyzates are common between polypropylene NPs and NOM, their potential coelution of NOM and polypropylene markers was thus investigating. Polypropylene identification was performed by spiking polypropylene NPs into the three different OM (Materials and Methods section). For the SAWE, the polypropylene/OM ratio $(\mathrm{g} / \mathrm{g})$ was set to 0.073 , correspondings to $2 \mu \mathrm{gC}$ of polypropylene and $27.5 \mu \mathrm{gC}$ of SAWE. For LNOM and LHA, the polypropylene/OM ratio $(\mathrm{g} / \mathrm{g})$ was set to 0.011 , corresponding to $2 \mu \mathrm{gC}$ of polypropylene and 175 $\mu \mathrm{gC}$ of $\mathrm{OM}$. Leonardite organic matter pyrograms with and without polypropylene NPs were compared to identify potential coeluted pyrolyzates at the retention times of $\mathrm{C} 9, \mathrm{C} 12$, and both C15 compounds. 
For polypropylene NPs spiked into SAWE, at $\mathrm{m} / \mathrm{z} 70$ (Figure $3 \mathrm{~A}$ ), the pyrogram showed a significant peak at the retention time of $\mathrm{C} 9$. At $\mathrm{m} / \mathrm{z} 69$, the three other polypropylene markers are observed in the pyrogram (Figure 3B). Without polypropylene NPs, the mass spectra did not show any similarity with the reference, confirming that SAWE and polypropylene have no homopyrolyzate interferences, as previously discussed (Table S1). The mass spectra for polypropylene NPs spiked into SAWE showed a very high similarity with polypropylene for the following markers: C9, C15i, and C15s (Figure 3C). These coeluted SAWE pyrolyzates were thus at too low concentration to interfere. Conversely, the $\mathrm{C} 12$ spectra were not similar due to the presence of a coeluted OM pyrolyzates, which contributed to the C12 mass spectrum (Figure 3C). Therefore, only $\mathrm{C} 12$ has coeluted-pyrolyzate interference with SAWE.

For polypropylene NPs spiked into LNOM (Fig S7), the $\mathrm{m} / \mathrm{z} 70$ and $\mathrm{m} / \mathrm{z} 69$ pyrograms showed a significant peak increase for all the polypropylene markers compared to non-spiked LNOM. The peaks at polypropylene retention times remained low compared to those of OM. The LNOM mass spectra with and without polypropylene NPs were different. No homo-pyrolyzate interferences are observed between LNOM and polypropylene. For LHA, a significant peak increase was observed for pyrograms with and without polypropylene NPs at all polypropylene markers' retention times (Fig S8). The polypropylene markers are thus very distinctive. No mass spectrum similarities are obtained between polypropylene markers and LHA. As observed for SAWE and NOM, no homopyrolyzate interference exists between LHA and polypropylene. With polypropylene NPs, the mass spectra were similar for the polypropylene markers (Figure 3C). No coeluted-pyrolyzate is observed. Thus, polypropylene can be directly identified with all four selected markers.

In summary, coeluted-pyrolyzate interference is identified for C12 for SAWE and NOM. Polypropylene was still identifiable because the three other markers had no interferences. The use of these three polypropylene markers allowed direct polypropylene identification in the three studied OM samples. Concerning the environmental identification of polypropylene, although OM was in excess (e.g., 14 times for SAWE and 100 for LNOM and LHA), all these ratios allowed polypropylene identification. Moreover, the $\mathrm{m} / \mathrm{z} 70$ pyrograms show that these ratios could be decreased and that polypropylene identification could be achieved using only the C9 marker. For LNOM and LHA, the polypropylene/OM ratio could be decreased since no peak is present at the retention time of C9 in both OM pyrogram without polypropylene NPs.

In contrast, the SAWE pyrogram without polypropylene NPs exhibited a peak at the retention time of C9. Therefore, over the polypropylene-OM ratio, the C9 marker could no longer be identified. By setting the limit when the C9 mass peak is equal to 2 times the SAWE coeluted pyrolyzate, it may be difficult to assess the presence of polypropylene in SAWE below a ratio of $0.025(\mathrm{~g} / \mathrm{g})$. 


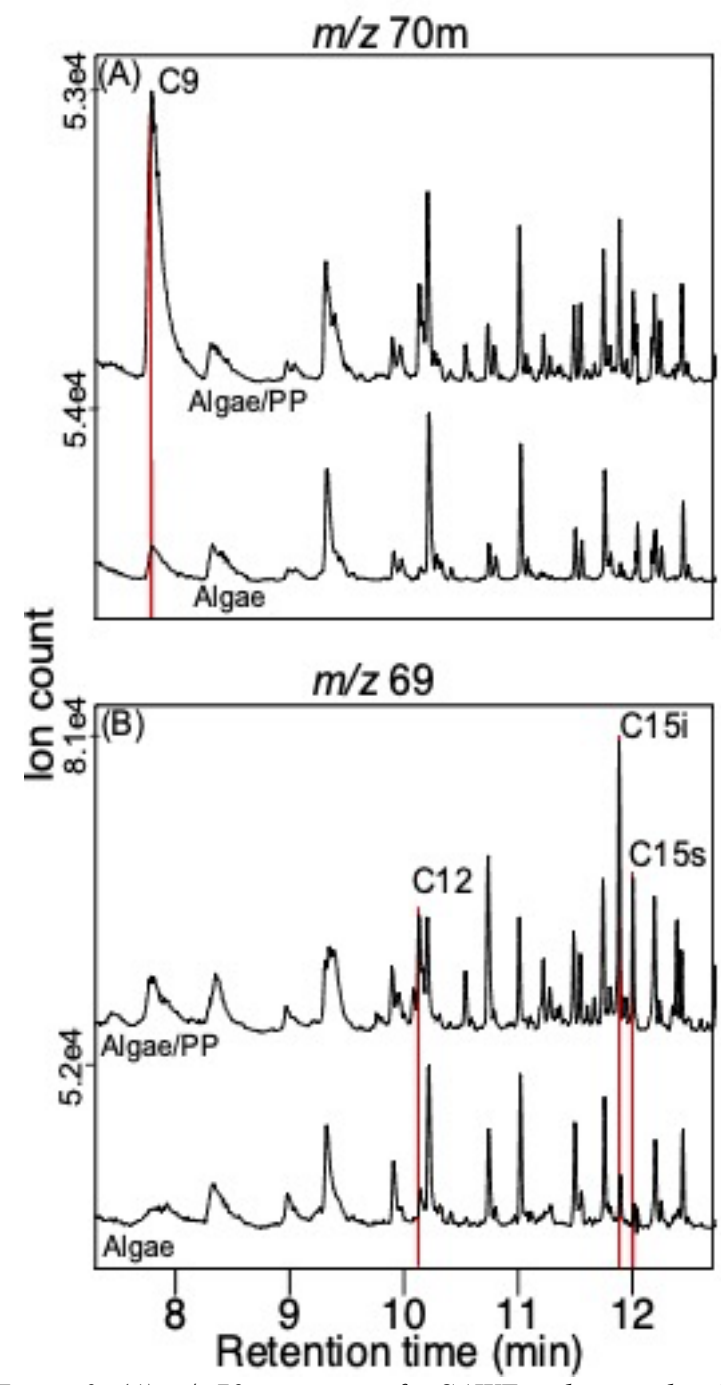

(C)
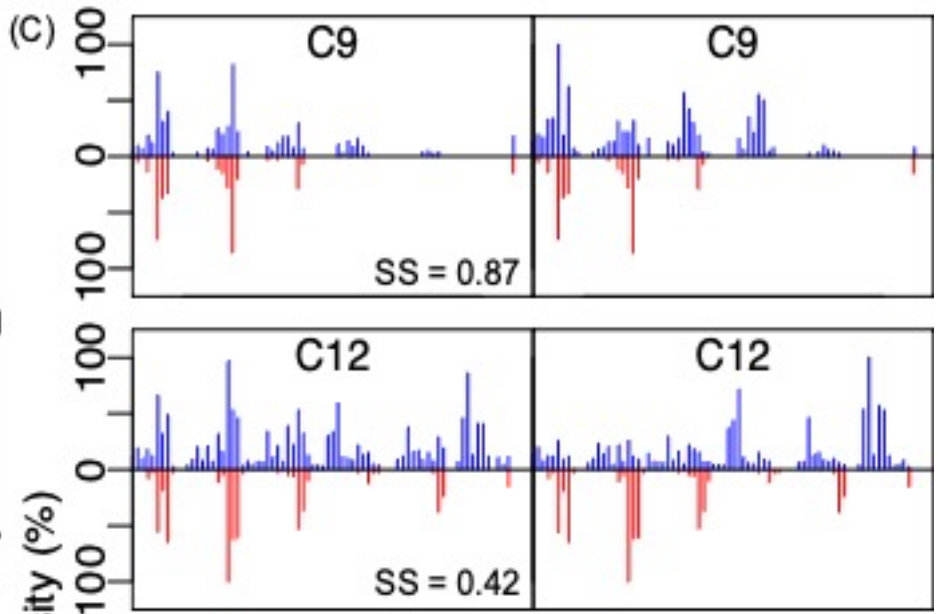

\section{.}
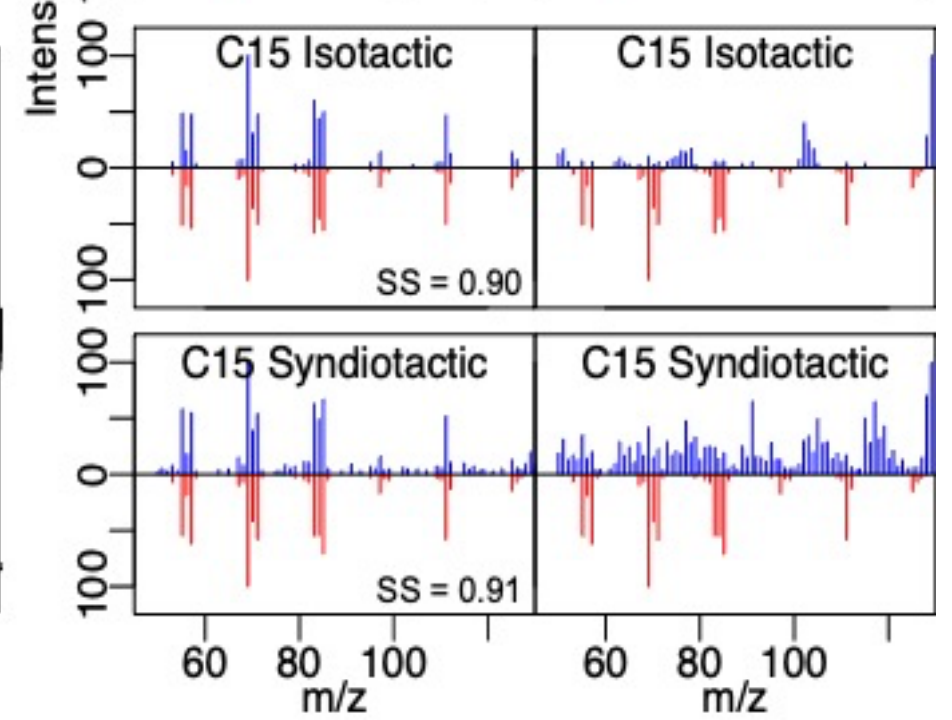

Figure 3: (A) $\mathrm{m} / \mathrm{z} 70$ pyrograms for SAWE without and with polypropylene NPs; (B) $\mathrm{m} / \mathrm{z} 69$ pyrograms for SAWE without and with polypropylene NPs; (C) Mass spectra of pyrolyzates recorded at polypropylene marker retention times (blue) and their library MSs (red).

Application to environmental nanoplastics

To evaluate the ability to identify the NPs composition in complex matrices, we applied the PyGCMS on environmental nanoplastics (EnvNPs). These EnvNPs were produced from unwashed beached plastics covered by Sargasso algae (e.g., type SAWE). Figure 4 illustrates the size and shape characterization of the EnvNPs obtained by DLS and TEM. The EnvNPs have a hydrodynamic diameter ranging from 200 to $500 \mathrm{~nm}$ (Figure 4), lower than the polystyrene and polypropylene nanoplastics. This difference can be described by the advanced oxidation state of the plastic debris sampled in the environment that more likely produces nanoscale particles. The EnvNPs are less size-polydispersed and better separated probably because NOM stabilized them differently according to their size. However, EnvNPs present an identical shape to polypropylene and polystyrene NPs (Figure 4). As for polypropylene $\mathrm{NPs}, \mathrm{TiO}_{2}$ and carbonates were identified. 
While $\mathrm{TiO}_{2}$ results from additive, carbonates could result from both additive and natural biotic or abiotic precipitates.
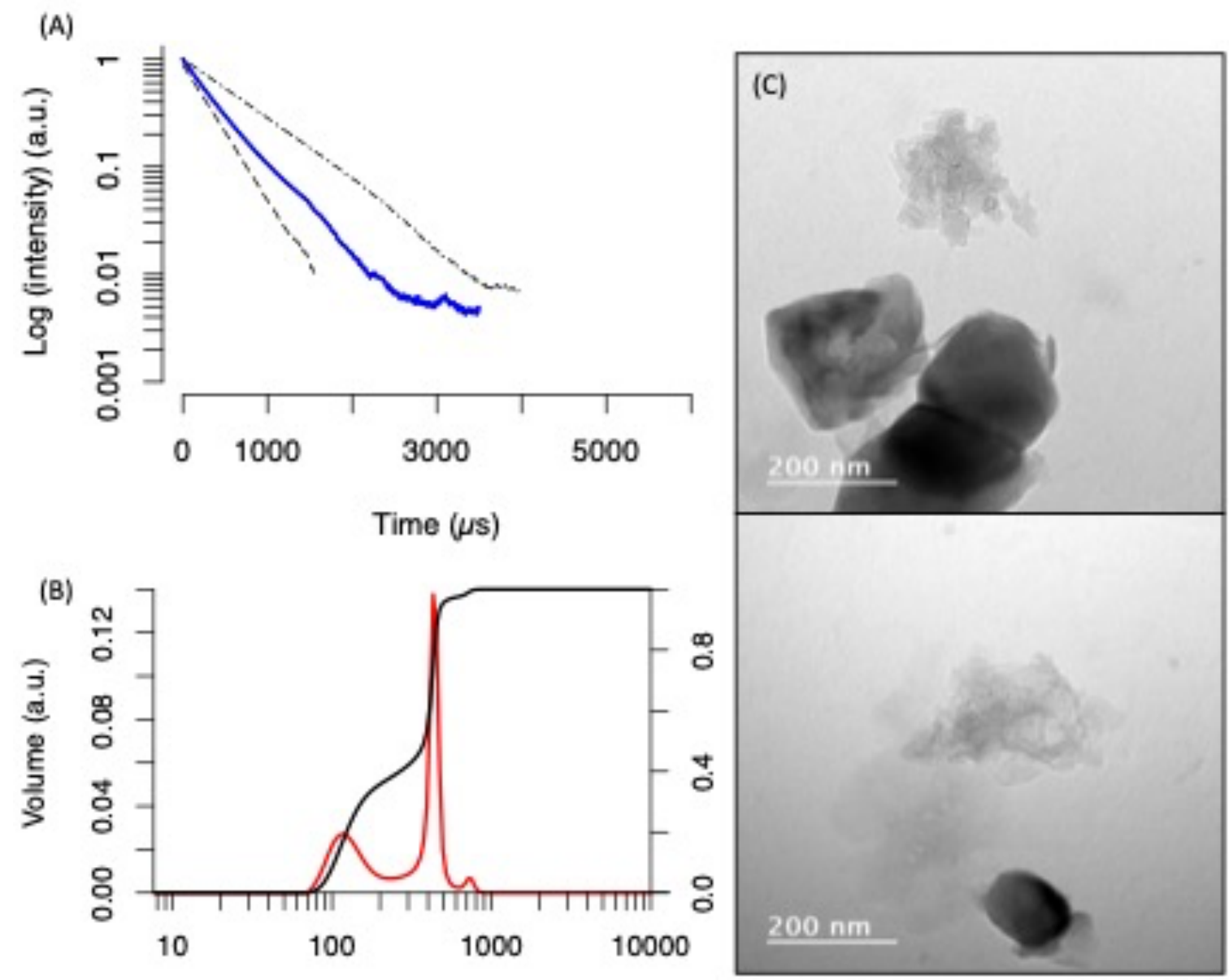

Diameter (nm)

Figure 4: (A) ACF function of the EnvNPs bordered by the 500 and $900 \mathrm{~nm}$ polystyrene spherical latex nanoparticles; (B) corresponding size distribution expressed in volume with the associated integration; (C) TEM images of EnvNPS.

The direct identification of polypropylene NPs was applied and validated with EnvNPs. For EnvNPs, on the $m / z 70$ pyrogram, an important peak occurred at the retention time of C9 (SI, Fig. S9). On the $m / z 69$ pyrogram, three other high-intensity peaks are distinct at the polypropylene markers' retention time: $\mathrm{C} 12, \mathrm{C} 15 \mathrm{i}$, and $\mathrm{C} 15 \mathrm{~s}$. For all of these peaks, comparisons of their mass spectra with those in the literature showed high similarities ( $\mathrm{SS}>0.90$, Figure S9). Therefore, even if NOM is highly present in the EnvNPs suspension, polypropylene is evidenced without further treatments.

However, concerning Polystyrene in the EnvNPs, identifying the styrene dimer and trimer pyrolyzates was not possible, as illustrated by the pyrograms in Figure 5 (Fig. 5A). Moreover, based on the TIC, a large range of signals and peaks are NOM characteristics without a clear indication of polystyrene. Also, the Tol/Sty ratio obtained for EnvNPs ranges from 4 to 5, suggesting that the Styrene signal $(\mathrm{m} / \mathrm{z} 104)$ can be attributed to NOM rather than polystyrene. 

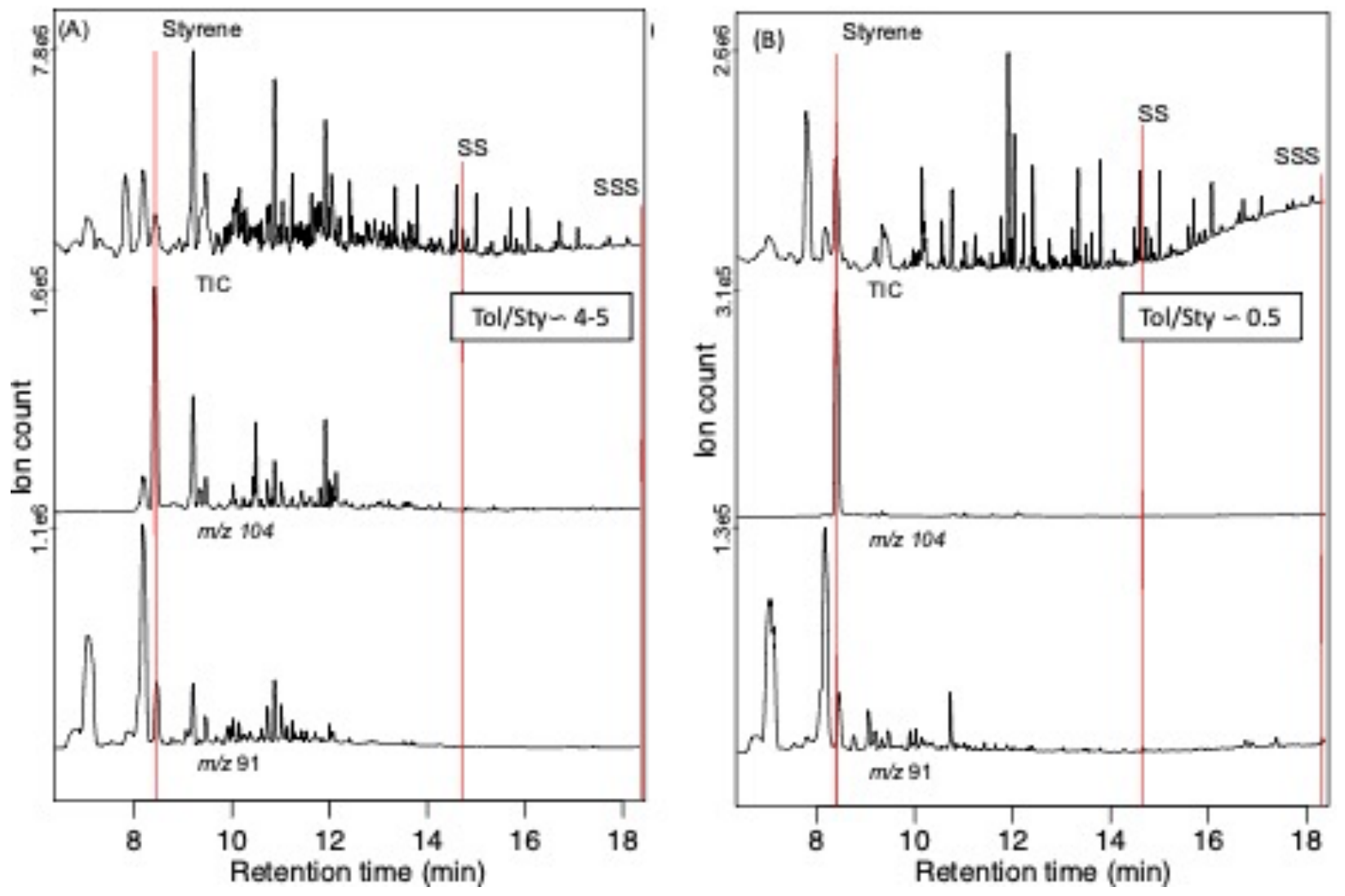

Figure 5: EnvNPs pyrograms for TIC, $\mathrm{m} / \mathrm{z} 104$ and $\mathrm{m} / \mathrm{z} 91$ (A) before and (B) after $\mathrm{H}_{2} \mathrm{O}_{2} /$ UV purification process.

Therefore, we developed a protocol using $\mathrm{H}_{2} \mathrm{O}_{2}$ and UV light ${ }^{36,37}$ to selectively degrade NOM without affecting the nanoplastics integrity by testing various experimental conditions. The optimized protocol consists of the $\mathrm{H}_{2} \mathrm{O}_{2}$ addition at $1 \%(\mathrm{v} / \mathrm{v})$ in the EnvNPs suspension and then exposition to UV light to induce $\mathrm{OH}$ radical reaction. This protocol allows the degrading of more than $90 \%$ of NOM (SI, Fig S10). During the $\mathrm{H}_{2} \mathrm{O}_{2} / \mathrm{UV}$ processes, the Tol/Sty ratio is followed over time and NOM degradation (Figure 6). As explained above, at $\mathrm{t}=0$, EnvNPs had a high Tol/Sty ratio suggesting that the styrene comes from NOM as expected by the large amount of NOM associated with the plastics debris ${ }^{35,38}$. After twenty-four hours of UV, the Tol/Sty ratio decreases to reach a ratio around 0.5 , highly similar to the polystyrene NPs' ratio (Fig. 5B). It is worth noting that after EnvNPs purification from NOM, the $\mathrm{m} / \mathrm{z} 104$ pyrogram presents both a cleaner and twice intense chromatogram with a clear styrene peak $(\mathrm{t} R=8.2 \mathrm{~min})$. At the same time, the carbon mass significantly decreased with the $\mathrm{H}_{2} \mathrm{O}_{2}$ /UV light action. Such combined observation confirms, afterall, the polystyrene occurrence in the EnvNPs suspension.

Additionally, the detection of the styrene is significantly enhanced after the $\mathrm{H}_{2} \mathrm{O}_{2} / \mathrm{UV}$ treatment. This result is coherent with: (i) the better sensitivity of the PyGCMS to detect styrene pyrolyzate for polystyrene vs. NOM since styrene is the principal component of polystyrene; (ii) the NOM effect on the signal attenuation previously demonstrated for styrene for Nps detection in soil ${ }^{6}$. Moreover, the major pyrolyzate of polypropylene (i.e., C9, C12, C15i, and s) were still identified (SI, Fig. S11). The combination of both strategies is thus appropriate to detect them in complex environmental matrices. 


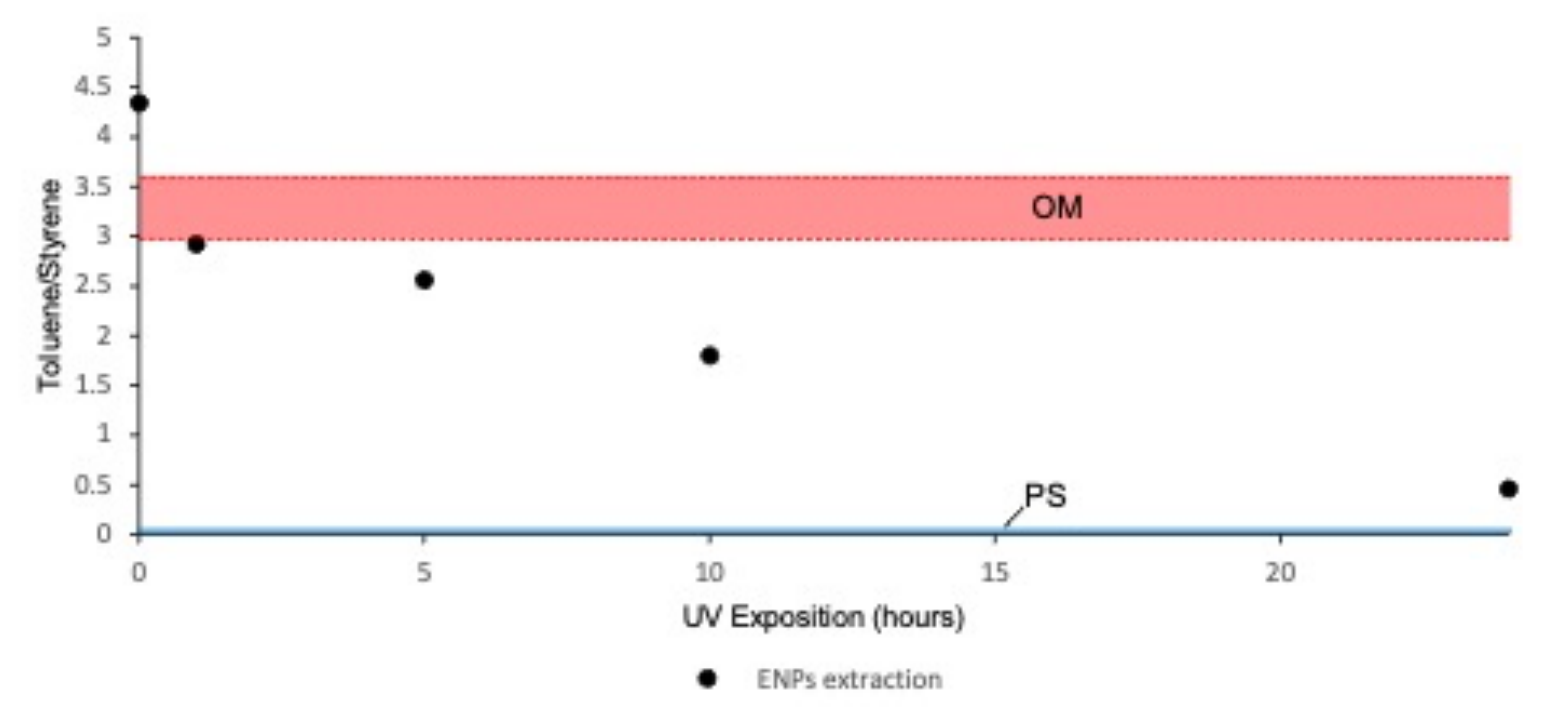

Figure 6: Toluene/Styrene ratio evolution during the OM degradation applied on the EnvNPs suspension. The red zone indicated the toluene/styrene ratio obtained to the different studied NOM. The blue zone indicated the toluene/styrene ratio obtained for the polystyrene microscale pellet and polystyrene NPS.

\section{Supporting Information}

The following files are available free of charge. An example of plastic-coated on Sargasso algae (Figure S1); Size description of the nanoplastic models (Fig. S2). TEM image and EDX spectra from a nanoplastic and the TEM grid (Figure S3). Polypropylene and polystyrene pre-selected pyrolyzates and peak information obtained from both micro and nanoscale plastics pyrolysis (Fig. S4, S5, S6, and Table S1 S2). Standards and Environmental nanoplastics pyrograms with and without natural organic matters (Fig. S7, S8, S9, S11). Evaluation of the degradation efficiency of the natural organic matter (Fig. S10).

\section{Corresponding Author}

*E-mail address: julien.gigault@takuvik.ulaval.ca (ORCID 0000-0002-2988-8942)

†TAKUVIK, CNRS / Université Laval, Québec (Québec) G1V 0A6, Canada

\section{Notes}

There are no conflicts to declare.

\section{Acknowledgments}

This work was supported by the ANR (Agence Nationale de la Recherche) PRC program through the PEPSEA project (ANR-17-CE34-0008-05). We acknowledge funding and support from the Nouvelle-Aquitaine Region (En-Pi project), which lead to the development of the "topdown" nanoplastics. We also acknowledge Ludivine Rault for her help during TEM observations performed at THEMIS 476 (ScanMAT, UMS 2001 CNRS - University of Rennes 1). 


\section{Abbreviations}

C9, 2,4-dimethyl-1-heptene; C10, 2,4,6-trimethyl-1-heptene; C12, meso-2,4,6-trimethyl-1nonene; C15i, isotactic-2,4,6,8-tetramethyl-1-undecene; C15s, syndiotactic-2,4,6,8-tetramethyl1-undecene.

\section{Synopsis}

Single out the NANOPLASTICS in environmental matrices is still challenging; this study provides evidence of Nanoplastics direct identification by Py-GCMS.

\section{References}

(1) Andrady, A. L. Microplastics in the Marine Environment. Marine Pollution Bulletin 2011, 62 (8), 1596-1605. https://doi.org/10.1016/j.marpolbul.2011.05.030.

(2) Gigault, J.; Pedrono, B.; Maxit, B.; Ter Halle, A. Marine Plastic Litter: The Unanalyzed Nano-Fraction. Environmental Science: Nano 2016, 3 (2), 346-350. https://doi.org/10.1039/c6en00008h.

(3) Lambert, S.; Wagner, M. Characterisation of Nanoplastics during the Degradation of Polystyrene. Chemosphere 2016, 265-268. https://doi.org/10.1016/j.chemosphere.2015.11.078.

(4) Ter Halle, A.; Jeanneau, L.; Martignac, M.; Jardé, E.; Pedrono, B.; Brach, L.; Gigault, J. Nanoplastic in the North Atlantic Subtropical Gyre. Environmental Science \& Technology 2017, 51 (23), 13689-13697. https://doi.org/10.1021/acs.est.7b03667.

(5) Davranche, M.; Lory, C.; Juge, C. L.; Blancho, F.; Dia, A.; Grassl, B.; El Hadri, H.; Pascal, P.-Y.; Gigault, J. Nanoplastics on the Coast Exposed to the North Atlantic Gyre: Evidence and Traceability. NanoImpact 2020, 100262. https://doi.org/10.1016/j.impact.2020.100262.

(6) Wahl, A.; Le Juge, C.; Davranche, M.; El Hadri, H.; Grassl, B.; Reynaud, S.; Gigault, J. Nanoplastic Occurrence in a Soil Amended with Plastic Debris. Chemosphere 2021, 262, 127784. https://doi.org/10.1016/j.chemosphere.2020.127784.

(7) Hartmann, N. B.; Hüffer, T.; Thompson, R. C.; Hassellöv, M.; Verschoor, A.; Daugaard, A. E.; Rist, S.; Karlsson, T.; Brennholt, N.; Cole, M.; Herrling, M. P.; Hess, M. C.; Ivleva, N. P.; Lusher, A. L.; Wagner, M. Are We Speaking the Same Language? Recommendations for a Definition and Categorization Framework for Plastic Debris. Environ. Sci. Technol. 2019, 53 (3), 1039-1047. https://doi.org/10.1021/acs.est.8b05297.

(8) Gigault, J. Current Opinion: What Is a Nanoplastic? Environ. Pollut 2018, 235, 1030-1034.

(9) Gigault, J.; El Hadri, H.; Nguyen, B.; Grassl, B.; Rowenczyk, L.; Tufenkji, N.; Feng, S.; Wiesner, M. Nanoplastics Are Neither Microplastics nor Engineered Nanoparticles. Nature Nanotechnology 2021, 1-7. https://doi.org/10.1038/s41565-021-00886-4.

(10) Geyer, R.; Jambeck, J. R.; Law, K. L. Production, Use, and Fate of All Plastics Ever Made. Science Advances 2017, 3 (7), e1700782. https://doi.org/10.1126/sciadv.1700782. 
(11) Plastics Europe. Plastics - the Facts 2017; (PlasticsEurope, Brussels, Belgium, 2017), 2017.

(12) Reisser, J.; Shaw, J.; Wilcox, C.; Hardesty, B. D.; Proietti, M.; Thums, M.; Pattiaratchi, C. Marine Plastic Pollution in Waters around Australia: Characteristics, Concentrations, and Pathways. PLoS ONE 2013, 8 (11), e80466. https://doi.org/10.1371/journal.pone.0080466.

(13) Brignac, K. C.; Jung, M. R.; King, C.; Royer, S.-J.; Blickley, L.; Lamson, M. R.; Potemra, J. T.; Lynch, J. M. Marine Debris Polymers on Main Hawaiian Island Beaches, Sea Surface, and Seafloor. Environ. Sci. Technol. 2019, $53 \quad$ (21), 12218-12226. https://doi.org/10.1021/acs.est.9b03561.

(14) Okoffo, E. D.; Ribeiro, F.; O’Brien, J. W.; O’Brien, S.; Tscharke, B. J.; Gallen, M.; Samanipour, S.; Mueller, J. F.; Thomas, K. V. Identification and Quantification of Selected Plastics in Biosolids by Pressurized Liquid Extraction Combined with Double-Shot Pyrolysis Gas Chromatography-Mass Spectrometry. Science of The Total Environment 2020, 715, 136924. https://doi.org/10.1016/j.scitotenv.2020.136924.

(15) Dierkes, G.; Lauschke, T.; Becher, S.; Schumacher, H.; Földi, C.; Ternes, T. Quantification of Microplastics in Environmental Samples via Pressurized Liquid Extraction and Pyrolysis-Gas Chromatography. Anal Bioanal Chem 2019, 411 (26), 6959-6968. https://doi.org/10.1007/s00216019-02066-9.

(16) Zhao, Y.-B.; Gao, P.-P.; Ni, H.-G. A Chemical Time Bomb: Future Risks of Microplastics. Water Air Soil Pollut 2019, 230 (11), 268. https://doi.org/10.1007/s11270-019-4320-9.

(17) Wilcox, C.; Hardesty, B. D.; Law, K. L. Abundance of Floating Plastic Particles Is Increasing in the Western North Atlantic Ocean. Environ. Sci. Technol. 2020, 54 (2), 790-796. https://doi.org/10.1021/acs.est.9b04812.

(18) Nguyen, B.; Claveau-Mallet, D.; Hernandez, L. M.; Xu, E. G.; Farner, J. M.; Tufenkji, N. Separation and Analysis of Microplastics and Nanoplastics in Complex Environmental Samples. Acc. Chem. Res. 2019, 52 (4), 858-866. https://doi.org/10.1021/acs.accounts.8b00602.

(19) Dümichen, E.; Eisentraut, P.; Bannick, C. G.; Barthel, A.-K.; Senz, R.; Braun, U. Fast Identification of Microplastics in Complex Environmental Samples by a Thermal Degradation Method. Chemosphere 2017, 174, 572-584. https://doi.org/10.1016/j.chemosphere.2017.02.010.

(20) Dümichen, E.; Barthel, A.-K.; Braun, U.; Bannick, C. G.; Brand, K.; Jekel, M.; Senz, R. Analysis of Polyethylene Microplastics in Environmental Samples, Using a Thermal Decomposition Method. Water Research 2015, 85, 451-457. https://doi.org/10.1016/j.watres.2015.09.002.

(21) Watteau, F.; Dignac, M.-F.; Bouchard, A.; Revallier, A.; Houot, S. Microplastic Detection in Soil Amended With Municipal Solid Waste Composts as Revealed by Transmission Electronic Microscopy and Pyrolysis/GC/MS. Front. Sustain. Food Syst. 2018, 2, 81. https://doi.org/10.3389/fsufs.2018.00081.

(22) Stoloff, L.; Silva, P. An Attempt to Determine Possible Taxonomic Significance of the 
Properties of Water Extractable Polysaccharides in Red Algae. Econ Bot 1957, 11 (4), 327-330. https://doi.org/10.1007/BF02903813.

(23) El Hadri, H.; Gigault, J.; Maxit, B.; Grass1, B.; Reynaud, S. Nanoplastic from Mechanically Degraded Primary and Secondary Microplastics for Environmental Assessments. NanoImpact 2020, 17, 100206. https://doi.org/10.1016/j.impact.2019.100206.

(24) Davranche, M.; Veclin, C.; Pierson-Wickmann, A.-C.; El Hadri, H.; Grassl, B.; Rowenczyk, L.; Dia, A.; Ter Halle, A.; Blancho, F.; Reynaud, S.; Gigault, J. Are Nanoplastics Able to Bind Significant Amount of Metals? The Lead Example. Environmental Pollution 2019, 249, 940-948. https://doi.org/10.1016/j.envpol.2019.03.087.

(25) Maguire, C. M.; Rösslein, M.; Wick, P.; Prina-Mello, A. Characterisation of Particles in Solution - a Perspective on Light Scattering and Comparative Technologies. Sci Technol Adv Mater 2018, 19 (1), 732-745. https://doi.org/10.1080/14686996.2018.1517587.

(26) Nyeo, S.-L.; Ansari, R. R. Sparse Bayesian Learning for the Laplace Transform Inversion in Dynamic Light Scattering. Journal of Computational and Applied Mathematics 2011, 235 (8), 2861-2872. https://doi.org/10.1016/j.cam.2010.12.008.

(27) Dehaut, A.; Cassone, A.-L.; Frère, L.; Hermabessiere, L.; Himber, C.; Rinnert, E.; Rivière, G.; Lambert, C.; Soudant, P.; Huvet, A.; Duflos, G.; Paul-Pont, I. Microplastics in Seafood: Benchmark Protocol for Their Extraction and Characterization. Environmental Pollution 2016, 215, 223-233. https://doi.org/10.1016/j.envpol.2016.05.018.

(28) Environmental Protection Agency. Definition and Procedure for the Determination of the Method Detection Limit, Revision 2; EPA 821-R-16-006; 2016.

(29) Graf, C.; Deggelmann, M.; Hagenbüchle, M.; Johner, C.; Kramer, H.; Krause, R.; Weber, R. Dynamic Light Scattering by Aqueous Solutions of Rod-Like FD-Virus Particles. In Structure and Dynamics of Strongly Interacting Colloids and Supramolecular Aggregates in Solution; Chen, S.-H., Huang, J. S., Tartaglia, P., Eds.; NATO ASI Series; Springer Netherlands: Dordrecht, 1992; pp 827-830. https://doi.org/10.1007/978-94-011-2540-6_46.

(30) Liu, H.; Pierre-Pierre, N.; Huo, Q. Dynamic Light Scattering for Gold Nanorod Size Characterization and Study of Nanorod-Protein Interactions. Gold Bull 2012, 45 (4), 187-195. https://doi.org/10.1007/s13404-012-0067-4.

(31) Hahladakis, J. N.; Velis, C. A.; Weber, R.; Iacovidou, E.; Purnell, P. An Overview of Chemical Additives Present in Plastics: Migration, Release, Fate and Environmental Impact during Their Use, Disposal and Recycling. Journal of Hazardous Materials 2018, 344, 179-199. https://doi.org/10.1016/j.jhazmat.2017.10.014.

(32) Sullivan, G. L.; Gallardo, J. D.; Jones, E. W.; Hollliman, P. J.; Watson, T. M.; Sarp, S. Detection of Trace Sub-Micron (Nano) Plastics in Water Samples Using Pyrolysis-Gas Chromatography Time of Flight Mass Spectrometry (PY-GCToF). Chemosphere 2020, 249, 126179. https://doi.org/10.1016/j.chemosphere.2020.126179.

(33) Nasa, J. L.; Biale, G.; Ferriani, B.; Trevisan, R.; Colombini, M. P.; Modugno, F. Plastics 
in Heritage Science: Analytical Pyrolysis Techniques Applied to Objects of Design. Molecules 2020, 25 (7), 1705. https://doi.org/10.3390/molecules 25071705.

(34) Fischer, M.; Scholz-Böttcher, B. M. Simultaneous Trace Identification and Quantification of Common Types of Microplastics in Environmental Samples by Pyrolysis-Gas Chromatography-Mass Spectrometry. Environ. Sci. Technol. 2017, 51 (9), 5052-5060. https://doi.org/10.1021/acs.est.6b06362.

(35) Fabbri, D.; Trombini, C.; Vassura, I. Analysis of Polystyrene in Polluted Sediments by Pyrolysis--Gas Chromatography--Mass Spectrometry. Journal of Chromatographic Science 1998, 36 (12), 600-604. https://doi.org/10.1093/chromsci/36.12.600.

(36) Wang, G.-S.; Liao, C.-H.; Wu, F.-J. Photodegradation of Humic Acids in the Presence of Hydrogen Peroxide. Chemosphere 2001, 42 (4), 379-387. https://doi.org/10.1016/S00456535(00)00153-3.

(37) Wang, G.-S.; Liao, C.-H.; Chen, H.-W.; Yang, H.-C. Characteristics of Natural Organic Matter Degradation in Water by UV/ $\mathrm{H}_{2} \mathrm{O}_{2}$ Treatment. Environmental Technology 2006, 27 (3), 277-287. https://doi.org/10.1080/09593332708618638.

(38) Dignac, M.-F.; Houot, S.; Francou, C.; Derenne, S. Pyrolytic Study of Compost and Waste Organic Matter. Organic Geochemistry 2005, 36 (7), 1054-1071. https://doi.org/10.1016/j.orggeochem.2005.02.007. 